\title{
Carbon Sequestration to Mitigate Climate Change
}

Human activities, especially the burning of fossil fuels such as coal, oil, and gas, have caused a substantial increase in the concentration of carbon dioxide $\left(\mathrm{CO}_{2}\right)$ in the atmosphere. This increase in atmospheric $\mathrm{CO}_{2}-$ from about 280 to more than 380 parts per million (ppm) over the last 250 years-is causing measurable global warming. Potential adverse impacts include sea-level rise; increased frequency and intensity of wildfires, floods, droughts, and tropical storms; changes in the amount, timing, and distribution of rain, snow, and runoff; and disturbance of coastal marine and other ecosystems. Rising atmospheric $\mathrm{CO}_{2}$ is also increasing the absorption of $\mathrm{CO}_{2}$ by seawater, causing the ocean to become more acidic, with potentially disruptive effects on marine plankton and coral reefs. Technically and economically feasible strategies are needed to mitigate the consequences of increased atmospheric $\mathrm{CO}_{2}$. The United States needs scientific information to develop ways to reduce human-caused $\mathrm{CO}_{2}$ emissions and to remove $\mathrm{CO}_{2}$ from the atmosphere.

\section{What is carbon sequestration?}

The term "carbon sequestration" is used to describe both natural and deliberate processes by which $\mathrm{CO}_{2}$ is either removed from the atmosphere or diverted from emission sources and stored in the ocean, terrestrial environments (vegetation, soils, and sediments), and geologic formations. Before human-caused $\mathrm{CO}_{2}$ emissions began, the natural processes that make up the global "carbon cycle" (fig. 1) maintained a near balance between the uptake of $\mathrm{CO}_{2}$ and its release back to the atmosphere. However, existing $\mathrm{CO}_{2}$ uptake mechanisms (sometimes called $\mathrm{CO}_{2}$ or carbon "sinks") are insufficient to offset the accelerating pace of emissions related to human activities. Annual carbon emissions from burning fossil fuels in the United States are about 1.6 gigatons (billion metric tons), whereas annual uptake amounts are only about 0.5 gigatons, resulting in a net release of about 1.1 gigatons per year (fig. 2).

\section{Atmosphere}

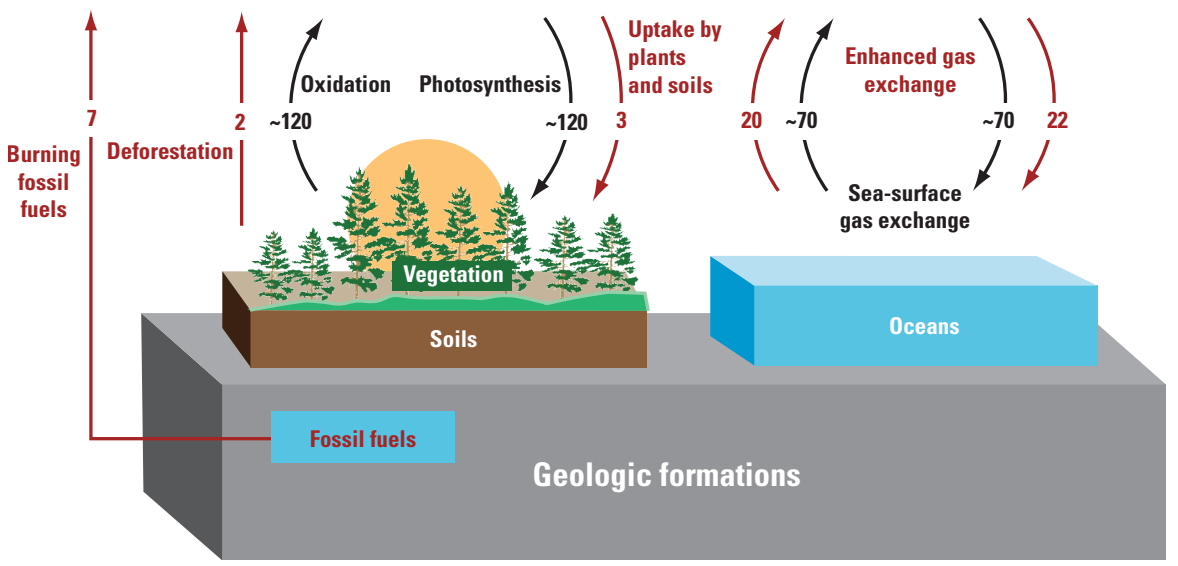

CARBON FLUX, IN GIGATONS PER YEAR

$\longrightarrow \sim$ Natural $\quad-20 \rightarrow$ Anthropogenic

Figure 1. The global carbon cycle. Carbon naturally moves, or cycles, between the atmosphere and vegetation, soils, and the oceans over time scales ranging from years to millennia and longer. Human activities, primarily the burning of fossil fuels and clearing of forests, have increased the transfer of carbon as $\mathrm{CO}_{2}$ to the atmosphere. Although some of this anthropogenic $\mathrm{CO}_{2}$ is removed from the atmosphere by the natural uptake processes ("sinks") of the carbon cycle, much of it remains in the atmosphere and causes rising $\mathrm{CO}_{2}$ concentrations. The goal of deliberate carbon sequestration is to decrease the net flux of $\mathrm{CO}_{2}$ to the atmosphere by sequestering carbon in the oceans, vegetation, soils, and porous rock formations. Fluxes shown are approximate for the period 2000-05, as documented by the Intergovernmental Panel on Climate Change.

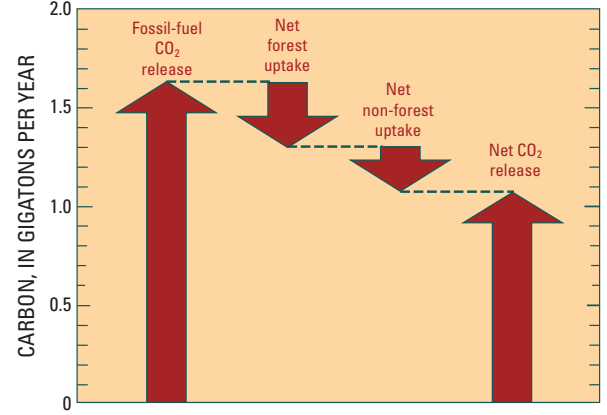

NET FLUX OF CARBON AS $\mathrm{CO}_{2}$

Figure 2. Estimated annual net $\mathrm{CO}_{2}$ emissions and uptake in the United States in 2003, according to the U.S. Climate Change Science Program. U.S. fossil-fuel $\mathrm{CO}_{2}$ emissions accounted for more than 20 percent of the global total in 2003. Net uptake fluxes (photosynthesis minus oxidation) are shown for forest and non-forest areas. The largest net U.S. $\mathrm{CO}_{2}$ uptake was associated with regrowing forests and harvesting wood products. Non-forest net carbon uptake-including accumulation in shrubs, agricultural soils, wetlands, rivers, and reservoirs - was smaller and more uncertain.

Controlling atmospheric $\mathrm{CO}_{2}$ will require deliberate mitigation with an approach that combines reducing emissions and increasing storage.

Scientists at the U.S. Geological Survey (USGS) and elsewhere are working to assess both the potential capacities and the potential limitations of the various forms of carbon sequestration and to evaluate their geologic, hydrologic, and ecological consequences. The USGS is providing information needed by decision makers and resource managers to maximize carbon storage while minimizing undesirable impacts on humans and their physical and biological environment. 


\section{Oceanic carbon sequestration}

The world's oceans are the primary long-term sink for human-caused $\mathrm{CO}_{2}$ emissions, currently accounting for a global net uptake of about 2 gigatons of carbon annually (fig. 1). This uptake is not a result of deliberate sequestration, but occurs naturally through chemical reactions between seawater and $\mathrm{CO}_{2}$ in the atmosphere. While absorbing atmospheric $\mathrm{CO}_{2}$, these reactions cause the oceans to become more acidic. Many marine organisms and ecosystems depend on the formation of carbonate skeletons and sediments that are vulnerable to dissolution in acidic waters. Laboratory and field measurements indicate that $\mathrm{CO}_{2}$-induced acidification may eventually cause the rate of dissolution of carbonate to exceed its rate of formation in these ecosystems. The impacts of ocean acidification and deliberate ocean fertilization on coastal and marine food webs and other resources are poorly understood. Scientists are studying the effects of oceanic carbon sequestration on these important environments.

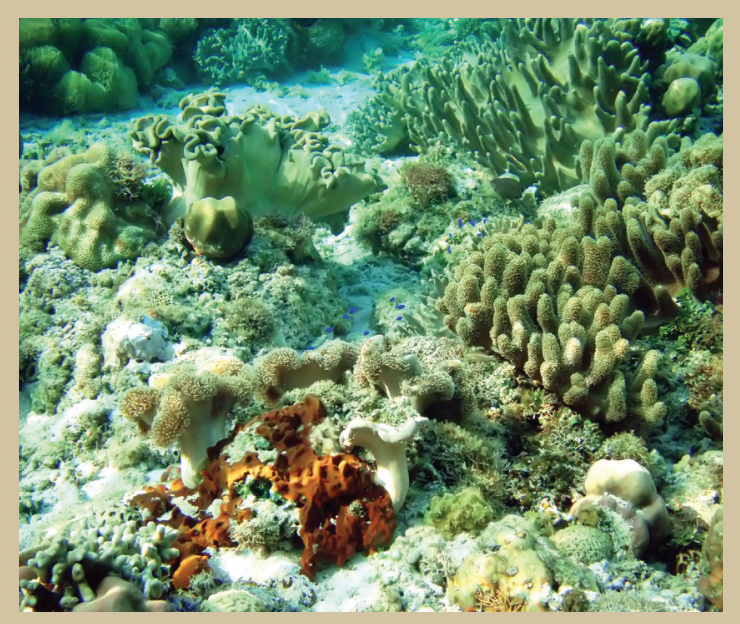

The term "carbon sequestration" is used to describe both natural and deliberate processes by which $\mathrm{CO}_{2}$ is either removed from the atmosphere or diverted from emission sources and stored in the ocean, terrestrial environments (vegetation, soils, and sediments), and geologic formations.

\section{Terrestrial carbon sequestration}

Terrestrial sequestration (sometimes termed "biological sequestration") is typically accomplished through forest and soil conservation practices that enhance the storage of carbon (such as restoring and establishing new forests, wetlands, and grasslands) or reduce $\mathrm{CO}_{2}$ emissions (such as reducing agricultural tillage and suppressing wildfires). In the United States, these practices are implemented to meet a variety of land-management objectives. Although the net terrestrial uptake fluxes shown in figure 2 offset about 30 percent of U.S. fossil-fuel $\mathrm{CO}_{2}$ emissions, only a small fraction of this uptake results from activities undertaken specifically to sequester carbon. The largest net uptake is due primarily to ongoing natural regrowth of forests that were harvested during the 19th and early 20th centuries.

Existing terrestrial carbon storage is susceptible to disturbances such as fire, disease, and changes in climate and land use. Boreal forests and northern peatlands, which store nearly half the total terrestrial carbon in North America, are
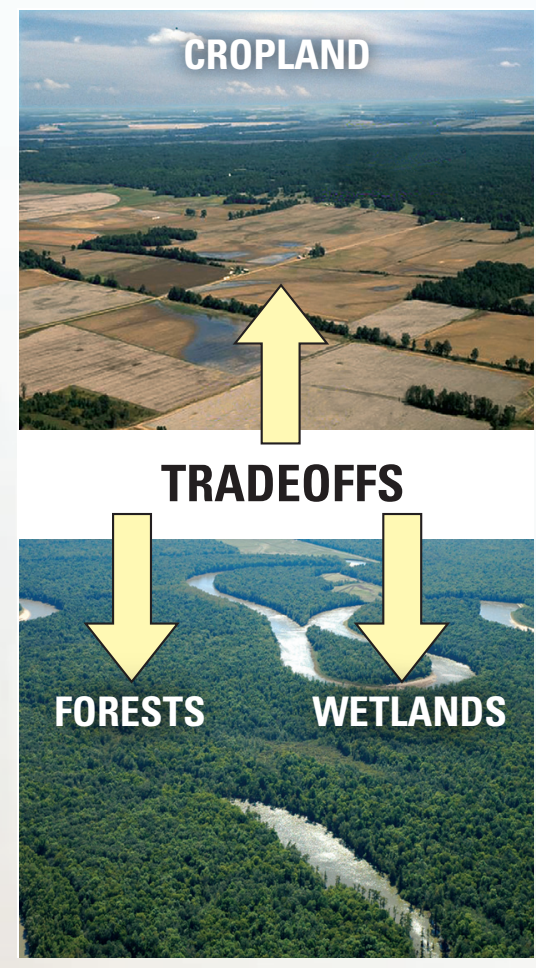
already experiencing substantial warming, resulting in large-scale thawing of permafrost and dramatic changes in aquatic and forest ecosystems. USGS scientists have estimated that at least 10 gigatons of soil carbon in Alaska is stored in organic soils that are extremely vulnerable to fire and decomposition under warming conditions.

The capacity of terrestrial ecosystems to sequester additional carbon is uncertain. An upper estimate of potential terrestrial sequestration in the U.S. might be the amount of carbon that would be accumulated if U.S. forests and soils were restored to their historic levels before they were depleted by logging and cultivation. These amounts (about 32 and 7 gigatons for forests and soils, respectively) are probably not attainable by deliberate sequestration because restoration on this scale would displace a large percentage of U.S. agriculture and disrupt many other present-day activities. Decisions about terrestrial carbon sequestration require careful consideration of priorities and tradeoffs among multiple resources. For example, converting farmlands to forests or wetlands may increase carbon sequestration, enhance wildlife habitat and water quality, and increase flood storage and recreational potential- but the loss of farmlands will decrease crop production. Converting existing conservation lands to intensive cultivation, while perhaps producing valuable crops (for example, for biofuels), may diminish wildlife habitat, reduce water quality and supply, and increase $\mathrm{CO}_{2}$ emissions. Scientists are working to determine the effects of climate and land-use change on potential carbon sequestration and ecosystem benefits, and to provide information about these effects for use in resource planning. 


\section{Geologic carbon sequestration}

Geologic sequestration begins with capturing $\mathrm{CO}_{2}$ from the exhaust of fossilfuel power plants and other major sources. The captured $\mathrm{CO}_{2}$ is piped 1 to 4 kilometers below the land surface and injected into porous rock formations (fig. 3). Compared to the rates of terrestrial carbon uptake shown in figures 1 and 2 , geologic sequestration is currently used to store only small amounts of carbon per year. Much larger rates of sequestration are envisioned to take advantage of the potential permanence and capacity of geologic storage.

The permanence of geologic sequestration depends on the effectiveness of several $\mathrm{CO}_{2}$ trapping mechanisms. After $\mathrm{CO}_{2}$ is injected underground, it will rise buoyantly until it is trapped beneath an impermeable barrier, or seal. In principle, this physical trapping mechanism, which is identical to the natural geologic trapping of oil and gas, can retain $\mathrm{CO}_{2}$ for thousands to millions of years. Some of the injected $\mathrm{CO}_{2}$ will eventually dis- solve in ground water, and some may be trapped in the form of carbonate minerals formed by chemical reactions with the surrounding rock. All of these processes are susceptible to change over time following $\mathrm{CO}_{2}$ injection. Scientists are studying the permanence of these trapping mechanisms and developing methods to determine the potential for geologically sequestered $\mathrm{CO}_{2}$ to leak back to the atmosphere.

The capacity for geologic carbon sequestration is constrained by the volume and distribution of potential storage sites. According to the U.S. Department of Energy, the total storage capacity of physical traps associated with depleted oil and gas reservoirs in the United States is limited to about 38 gigatons of carbon, and is geographically distributed in locations that are distant from most U.S. fossil-fuel power plants. The potential U.S. storage capacity of deep porous rock formations that contain saline ground water is much larger (estimated by the U.S. Department of Energy to be about 900 to 3,400 gigatons of carbon) and more widely distributed, but less is known about the effectiveness of trapping mechanisms at these sites. Unmineable coal beds have also been proposed for potential $\mathrm{CO}_{2}$ storage, but more information is needed about the storage characteristics and impacts of $\mathrm{CO}_{2}$ injection in these formations. Scientists are developing methods to refine estimates of the national capacity for geologic carbon sequestration.

To fully assess the potential for geologic carbon sequestration, economic costs and environmental risks must be taken into account. Infrastructure costs will depend on the locations of suitable storage sites. Environmental risks may include seismic disturbances, deformation of the land surface, contamination of potable water supplies, and adverse effects on ecosystems and human health. Scientists are pioneering the use of new geophysical and geochemical methods that can be used to anticipate the potential costs and environmental effects of geologic carbon sequestration.

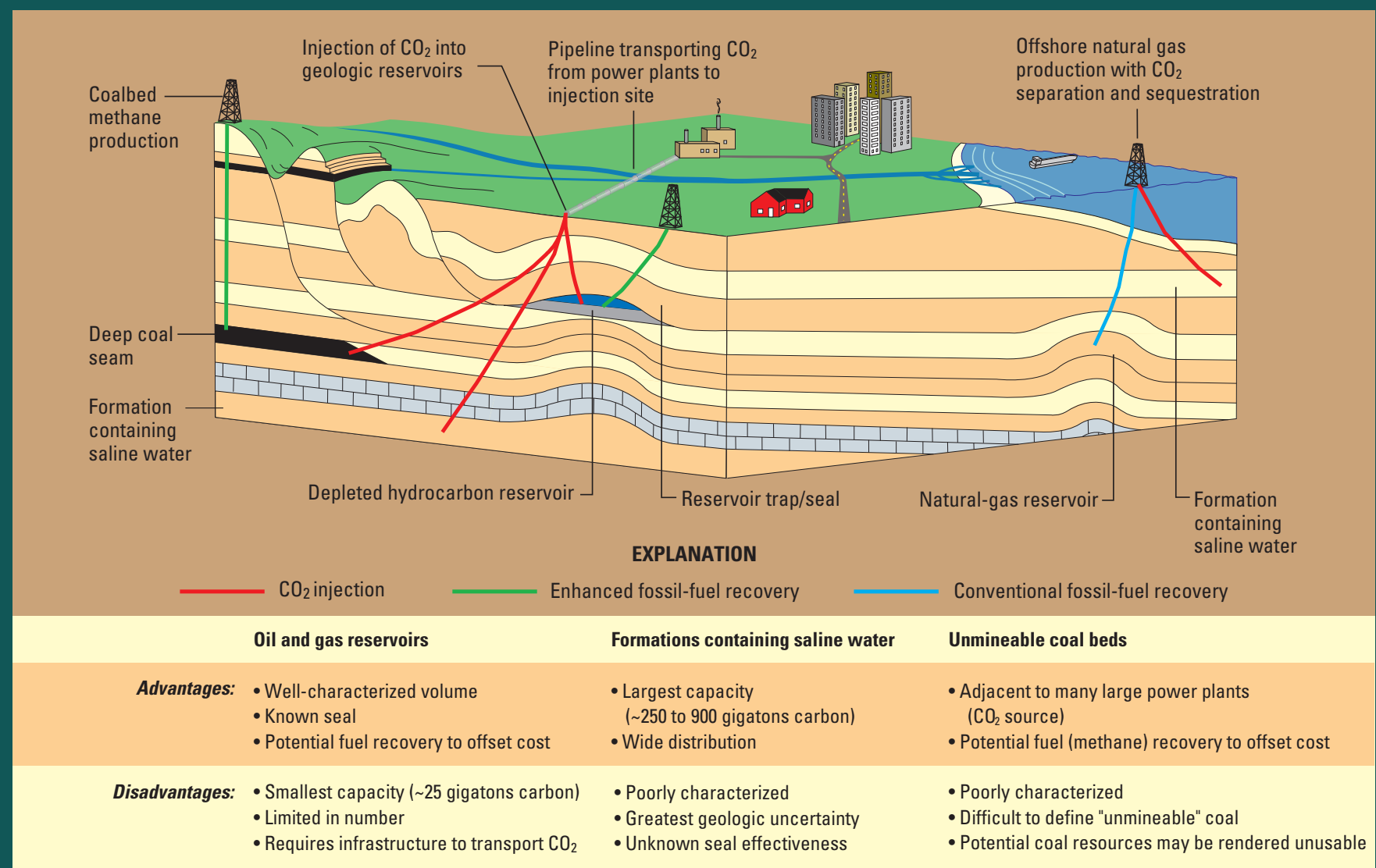

Environmental issues: Potential for mobilization of ground-water contaminants; leakage of $\mathrm{CO}_{2}$ and $\mathrm{CO}_{2}$-saturated saline water; induced seismicity

Regulatory issues: Determination of rules affecting injection wells; multiple regulatory jurisdictions (State, Federal, local); post-injection ownership and liability

Figure 3. Types of geologic $\mathrm{CO}_{2}$ sequestration, their advantages and disadvantages, and potential environmental and regulatory issues. Offshore natural-gas production and $\mathrm{CO}_{2}$ sequestration are currently occurring off the coast of Norway, where the gas produced contains a high concentration of $\mathrm{CO}_{2}$ that is removed and injected into a nearby formation containing saline water. 


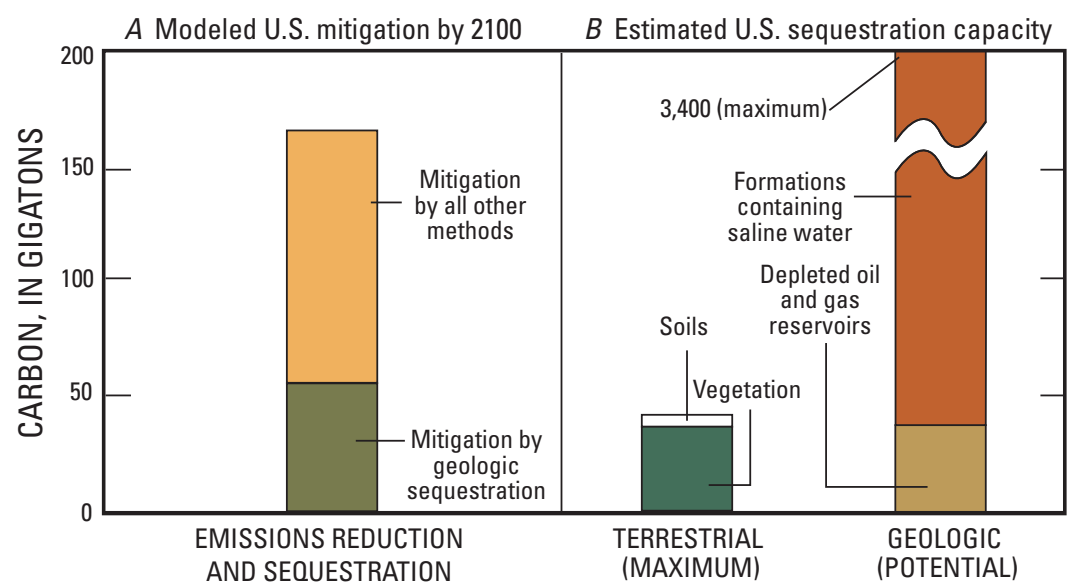

Figure 4. Estimated U.S. atmospheric $\mathrm{CO}_{2}$ (as carbon) mitigation needs and potential sequestration capacities: (A) Cumulative U.S. $\mathrm{CO}_{2}$ emissions reduction and sequestration needed by 2100 to help stabilize atmospheric $\mathrm{CO}_{2}$ at 550 parts per million (model results from U.S. Climate Change Science Program); (B) Estimated U.S. $\mathrm{CO}_{2}$ sequestration capacity. (The estimate of $\sim 3,400$ gigatons carbon for potential geologic storage is equivalent to $\sim 12,600$ gigatons $\mathrm{CO}_{2}$, as estimated by the U.S. Department of Energy. Terrestrial sequestration is not expected to approach the estimate shown. Uncertainties in estimated terrestrial and geologic sequestration are substantial.)

\section{Why action is needed now}

Cumulative historical $\mathrm{CO}_{2}$ emissions from fossil fuels in the United States are equivalent to more than the total amount of carbon stored in U.S. forests. If current trends continue, cumulative U.S. emissions are projected to double by 2050 and increase by a factor of three to four by 2100. According to the Intergovernmental Panel on Climate Change Fourth Assessment Report of 2007, sequestration and reduction of emissions over the next two to three decades will potentially have a substantial impact on longterm opportunities to stabilize levels of atmospheric $\mathrm{CO}_{2}$ and mitigate impacts of climate change.

\section{Can sequestration control atmospheric $\mathrm{CO}_{2}$ ?}

Computer models of future $\mathrm{CO}_{2}$ emissions and controls on atmospheric $\mathrm{CO}_{2}$ have been developed and summarized by the U.S. Climate Change Science Program (CCSP). These models indicate that projected annual global emissions during the next century would need to be reduced by more than 75 percent in order to stabilize atmospheric $\mathrm{CO}_{2}$ at about 550 ppm. This concentration would be about twice the level of $\mathrm{CO}_{2}$ in the pre-industrial atmosphere and about 45 percent higher than the atmospheric $\mathrm{CO}_{2}$ concentration in 2007. According to the CCSP, stabilizing atmospheric $\mathrm{CO}_{2}$ would "require a transformation of the global energy system, including reductions in the demand for energy.... and changes in the mix of energy technology and fuels."
The CCSP models have been used to evaluate scenarios for aggressive implementation of geologic carbon sequestration. As shown in figure 4A, the estimated amount of geologic sequestration in the U.S. over the next century is projected in one model to be substantially smaller than the cumulative emission reductions anticipated from changes by all other methods. In this model, the needed amount of geologic sequestration would exceed U.S. capacity in depleted oil and gas reservoirs, implying the need to implement carbon storage in the Nation's relatively unknown deep formations that contain saline water. In other models, predicted geologic sequestration needs are smaller as a result of different assumptions about global and national economic and technological trends.

The CCSP model results have a large amount of uncertainty. The results shown in figure 4 do not take into account many of the uncertainties in costs and environmental risks of geologic carbon sequestration. Additional uncertainties prevent comparison of future oceanic and deliberate terrestrial sequestration. Future disturbances of vegetation and soils may add to future $\mathrm{CO}_{2}$ emissions and increase the amount of mitigation required to stabilize atmospheric $\mathrm{CO}_{2}$. For example, if a substantial portion of the carbon stored in Alaskan organic soils were converted to atmospheric $\mathrm{CO}_{2}$ as a result of climate change, the resulting emissions could offset or even exceed the likely magnitude of any deliberate U.S. terrestrial sequestration measures.
The CCSP models illustrate the widely held view that sequestration is necessary but insufficient to control atmospheric $\mathrm{CO}_{2}$. Stabilizing atmospheric $\mathrm{CO}_{2}$ is likely to require substantial changes in energy sources and use as well as carbon management. Many of these changes will likely have significant, long-lasting impacts on land, water, and ecosystem resources.

\section{How the USGS is helping}

The USGS is committed to acquiring and communicating the scientific information needed to control atmospheric $\mathrm{CO}_{2}$ and minimize its harmful effects on natural resources. For many years, USGS scientists have contributed to the growing body of knowledge concerning climate change, the carbon cycle, and carbon sequestration. Building on its tradition of providing reliable, impartial scientific information to support the management of natural resources, the USGS provides information to support carbon management by:

- applying the expertise of many technical disciplines to understand how to limit $\mathrm{CO}_{2}$ emissions and maximize carbon storage;

- integrating information about the multiple resources that will be affected by carbon management decisions; and

- communicating scientific information across the many jurisdictions and organizations responsible for and affected by carbon management.

The USGS is providing information needed to assess the need for $\mathrm{CO}_{2}$ mitigation, evaluate the potential for carbon sequestration to meet that need, and anticipate the potential environmental consequences of implementing the full portfolio of strategies for controlling atmospheric $\mathrm{CO}_{2}$.

By Eric Sundquist, Robert Burruss, Stephen Faulkner, Robert Gleason,

Jennifer Harden, Yousif Kharaka,

Larry Tieszen, and Mark Waldrop

Edited by Dale L. Simmons

Graphic design by Christine T. Mendelsohn

Figure 4 by Eric A. Morrissey and Sean Brennan

For additional information about this report, please contact Eric Sundquist

(esundqui@usgs.gov).

For additional information about the

U.S. Geological Survey, please visit our web site at http: //www.usgs.gov/. 